\title{
Modernization of Tax Administrations and Optimal Fiscal Policies*
}

\author{
Martin Besfamille $\quad$ Cecilia Parlatore Siritto
}

July 13, 2009

\begin{abstract}
Since Sandmo (1981), many articles have analyzed optimal fiscal policies in economies with tax evasion. All share a feature: they assume that the cost of enforcing the tax law is exogenous. However, governments often invest resources to reduce these enforcement costs. In a very simple model, we incorporate such investments in the analysis of an optimal fiscal policy. We characterize their optimal level and we show numerically how they interact with the other dimensions of the optimal fiscal policy. Finally, we highlight the differences between our results and those obtained in a model without investment in the tax administration.
\end{abstract}

Keywords: Tax administration - Tax rates - Tax evasion - Enforcement - Audit costs.

JEL Codes: D82 - H26 - H83

\footnotetext{
*We thank J. Conley (the editor), an associate editor and two anonymous referees for their helpful comments and suggestions. We also thank M. Arellano, L. Arozamena, S. Auguste, F. Balmaceda, R. Bebczuk, G. Casamatta, W. Cont, H. Cremer, P. De Donder, J. Dubra, E. Espino, N. Figueroa, R. Fischer, L. Gasparini, G. Glomm, M. Gonzalez Eiras, E. Kawamura, D. Mejía, F. Navajas, P. Pestieau, L. Quesada, M. Raybaudi-Massilia, A. Repetto, P. Sanguinetti, J. Slemrod, M. Solá, M. Tommasi, S. Urbiztondo, F. Weinschelbaum, S. Yitzhaki, participants at the 8th International Meeting of the Association for Public Economic Theory (Vanderbilt University, 2007), the Workshop on Public Economics and Growth (Universidad de Santiago de Chile, 2007) and seminar participants at Université de Toulouse, IAE, FIEL, CEA-Universidad de Chile, Universidad de San Andrés, Universidad Nacional de La Plata and Universidad Torcuato Di Tella for useful comments. We are also indebted to A. Bellofatto and G. Navarro for their research assistance. All remaining errors are our sole responsibility. Part of the paper has been written when M. Besfamille visited GREMAQ and IDEI (University of Toulouse), whose hospitality is gratefully acknowledged. M. Besfamille also thanks financial support from Fondation Maison des Sciences de l'Homme (Bourse "Hermes") and from FONCyT (Grant \#26113).

${ }^{\dagger}$ Corresponding author. Department of Economics, Universidad Torcuato Di Tella. E-mail: mbesfamille@utdt.edu

‡Department of Economics, New York University.
} 


\section{Introduction}

This paper analyzes optimal fiscal policies in economies with tax evasion. For most governments, tax evasion is a problem because it threats the equity and the efficiency of their fiscal policies (see Cowell 1985, and Skinner and Slemrod 1985). ${ }^{1}$ For this reason, governments react and adopt actions to assure compliance with the tax law. For example, audits are conducted to verify whether tax liabilities have been met and, if it is not the case, evaders are penalized.

However, this 'enforcement approach' is not sufficient to deal with tax evasion. As the public finance literature shows, the fight against tax evasion cannot be isolated from the design of the fiscal policy; the extent of tax evasion depends not only on the parameters that characterize the enforcement policy carried out by the tax administration (e.g. frequency of audits, level of fines) but also upon the structure of the tax law (e.g. tax rates). Therefore, as suggested by Allingham and Sandmo (1972) and then emphasized by Kolm (1973), the design of optimal fiscal policies or 'optimal tax systems' (in Slemrod's (1990) terminology) should also include all instruments that help to enforce the tax law.

Since Sandmo (1981), many articles have analyzed, in different settings, optimal taxenforcement policies. ${ }^{2}$ All share a feature: the cost of a single audit or the shape of the audit cost function ${ }^{3}$ is exogenous. The purpose of this paper is to relax this assumption, for the following two reasons. From a theoretical point of view, in modern microeconomic models costs are often endogenous because agents adopt decisions to change them (see Tirole 1988). Moreover, adopting such decisions is not only a theoretical possibility but, as the following paragraph illustrates, it also has a strong empirical support: governments do invest resources to reduce the enforcement cost of the tax law.

In 1998, the US Congress created a special 'Information Technology Investment' account, to fund IRS modernization activities (see The President's Commission to Study Capital Budgeting 1998). With these funds, in 1999, the IRS launched 'Business Systems Modernization', an ambitious multianual project to modernize its information technology infrastructure (see IRS 2000). One of the pillars of this (ongoing) project is the change of its main data system, called the Master File system. This system was developed in the 1960s and consists of large tape files stocked in one of the IRS's computer centers in Martinsburg (West Virginia). It stores the taxpaying histories of 227 million individuals and corporations, including every transaction between taxpayers and the IRS for the past 40 years (see Varon 2004). Among others, the Master File system has an important drawback. The entire process required to enter account data into the Master File and make the updated information available for researching taxpayer accounts can take from 4 to 6

\footnotetext{
${ }^{1}$ One can get a good idea about the quantitative importance of tax evasion by looking at the US example. The Internal Revenue Service (IRS) estimated a tax gap for tax year 2001 of U\$D 345 billion (IRS, 2006). This amounts to almost $15 \%$ of total tax revenue, which is far from being a negligeable figure.

${ }^{2}$ Among others, we can cite Usher (1986), Slemrod and Yitzhaki (1987), Border and Sobel (1987), Mookherjee and Png (1989), Cremer, Marchand and Pestieau (1990), Kaplow (1990), Mayshar (1991), Sanchez and Sobel (1993), Pestieau, Possen and Slutsky (1994, 2004), Slemrod (1994), Cremer and Gahvari (1994, 1995), Marhuenda and Ortuño-Ortín (1997) and Chander and Wilde (1998).

${ }^{3}$ In some models, e.g. Cowell (1985), the cost of a single audit is a function of the number of audits conducted.
} 
weeks (see US General Accounting Office 1999). Because of these delays, IRS employees frequently have inconsistent and out-of-date information about a given taxpayer. Under these circumstances, conducting timely audits and going after tax evaders is extremely difficult. The Business Systems Modernization project will replace the Master File system with the Customer Account Data Engine (CADE), which will allow IRS's employees to post changes and update taxpayers accounts and returns from their desks. As a result, according to IRS (2005), audit costs should decrease. ${ }^{4}$

Investments made by governments to modernize their tax administration have been either mentioned informally (see Snavely 1988, and Slemrod and Yitzhaki 2002) or studied empirically (see Hunter and Nelson 1996). But, to our knowledge, they have not been incorporated into the formal analysis of optimal fiscal policies so far. ${ }^{5}$ We address this issue in a simple three-stage model, with two classes of active agents: individuals and a government. Each individual can be poor or rich; the rich being the only to earn a taxable income. The government follows a social welfare criterion that incorporates aversion to inequality. In order to maximize its criterion, the government designs a fiscal policy, to be implemented by the tax administration. In the first stage of the model, the government invests resources to 'modernize' the tax administration. In the second stage, the government designs the tax law, which specifies the tax owed by the rich and the enforcement policy to be conducted later by the tax administration. We assume that the government has the ability to commit to this policy. Finally, in the last stage of the model, the tax administration collects taxes and enforces the tax law, as follows. As incomes are private information, individuals are requested to report them. Then, the tax administration audits reports according to the frequency pre-specified by the government and, known to individuals. If an audit discovers that a taxpayer has misreported, the tax administration taxes the evader according to his true income and imposes him an additional fine. With all revenues collected (taxes and fines, net of investment and audit costs), the government finances the provision of a public good. As in many other contributions to the literature on tax evasion, we assume that audits are perfect but costly. The main novelty of this paper is the formalization of the audit cost as a decreasing function of the investment and its productivity.

As a benchmark, we derive first the optimal fiscal policy under full information, when enforcement is not necessary. Then we move to asymmetric information and we solve the model backwards. As the government can commit to the tax and to the enforcement policy to be conducted in the third stage, in the second stage we characterize the optimal tax law adopting a mechanism design approach. Depending upon the value of the audit cost, two regimes emerge. In the first regime, when the audit cost is low, the tax administration only audits individuals that have reported to be poor. In order to attenuate the stake for evasion of the rich, the optimal tax is downwardly distorted with respect to the full information optimal tax. We show that the optimal tax and the audit probability decrease with the audit cost. As is usual in this kind of models, the optimal fine has only a deterrent role and

\footnotetext{
${ }^{4}$ Snavely (1988) shows that, by the end of the 80s, many US States had already invested in computer technology to improve auditing.

${ }^{5} \mathrm{Alm}$ (1996) asserts that there is a lack of analysis regarding the shape of the audit cost function. In the conclusion of their survey, Slemrod and Yitzhaki (2002) consider the rigorous study of the tax collection technology as one of the main venues for future research in the economic literature on tax evasion.
} 
is maximal. In the second regime, the audit cost is so high that the government prefers not to tax and so no enforcement takes place. Anticipating these decisions, in the first stage, the government chooses whether to invest in the tax administration to reduce its audit cost and, if so, how much to invest. This choice has an impact not only on the expected social welfare (because tax revenues are allocated to investment instead of being allocated to the public good) but can also fix under which regime the government and the tax administration will be afterwards. Although we prove that an optimal investment exists, we cannot completely characterize it in general, due to the non-concavity of the problem. When the optimal investment is strictly positive, the levels of the tax, the audit probability and the public good are higher than their respective levels without investment. Under this circumstance, we can derive some comparative statics results: optimal investment increases with taxable income and with the degree of aversion to inequality, but decreases with the cost of the public good.

Then, we simulate numerically the model to identify the optimal investment, to quantify the other components of the optimal fiscal policy (and see their relation with the optimal level of investment) and to confirm the comparative statics results mentioned above. The simulations show that incorporating the modernization of the tax administration in a model of optimal tax-enforcement policies modifies its results substantially. First, the simulations clarify the relation between investment and expenditures in audit. Although investment reduces the cost of each individual audit, the aggregate audit cost can increase. Moreover, investment and aggregate audit cost can be substitutes or complements. Second, the two different ways of modifying the income distribution (i.e. a change in the fraction of rich in the population or their taxable income) do not have the same impact upon the optimal level of investment. Finally, all simulations show that the public sector becomes more efficient: the fraction of tax collection used to provide public goods increases.

\subsection{Related literature}

From a methodological point of view, our model is a simplified version of Mookherjee and Png (1989) and Pestieau, Possen and Slutsky (2004). These authors assume that pretax incomes are exogenous and that taxes are lump-sum, like we do. Moreover, they also assume that individuals are risk averse ${ }^{6}$ Finally, adopting the mechanism design approach, they characterize optimal tax-enforcement policies. But, besides the fact that these authors take the audit cost as given, our model differs with theirs on two important aspects. First, we rule out of the model rewards for truthful reports, whereas Mookherjee and Png (1989) find that they are indeed optimal deterrents for tax evasion. Second, we include in the model the provision of public goods, whereas they follow the traditional 'optimal taxation' approach that fixes exogenously the government's revenue requirement. Our results at the second stage are similar to theirs, but neither of them obtain analytic solutions and comparative statics results for the optimal tax law, as we do.

Incorporating the provision of public goods into the design of optimal fiscal policies in a context of tax evasion makes our paper similar to Kolm (1973), Gottlieb (1985), Usher

\footnotetext{
${ }^{6}$ Border and Sobel (1987) also find optimal tax enforcement policies, but in a context where individuals are risk neutral.
} 
(1986), Kaplow (1990), Falkinger (1991), Mayshar (1991), Sanchez and Sobel (1993) and Balestrino and Galmarini (2003). However these articles do not include investments to modernize the tax administration in their analysis, whereas it is our main contribution. The interaction of these two features of the model enable us to analyze the efficiency of the public sector taken as a whole.

We are not the first to address administrative and technological issues in optimal taxation models. Slemrod and Kopczuk (2002) analyze optimal tax systems when the government controls an administrative instrument that directly affects the elasticity of taxable income with respect to tax rates. Our model adopts a different indirect approach: investment affects utilities but only via the optimal tax law, that ultimately depends upon the level of the audit cost. Regarding the tax administration's technology, Usher (1986) and Mayshar (1991) have already dealt with this item. These authors characterize the optimal amount of resources spent by governments in tax enforcement activities. To do that, they rely on reduced-form functions and assume a positive relation between these resources and the cost borne by individuals to escape from being detected (Usher)/the maximal tax collection (Mayshar). ${ }^{7}$ While these positive relations seem logical, our numerical results show that, when one incorporates investments that improve the cost structure of the tax administration in the model, the signs of these relations become less evident.

Finally, our model sheds new light on the question of the size and the composition of the tax administration's budget. Like many others (see Slemrod and Yitzhaki 1987, and Slemrod 1994), we take the budget of the audit section for the budget of the entire tax administration. By incorporating investment as another element of the tax administration's budget, we can show first that the relation between the audit probability and the tax administration's budget is not so direct as in Slemrod and Yitzhaki (1987). Second, we can argue about the composition of this budget, as in Wertz (1979). In particular, we can see whether the investment is substitute or complement to the aggregate audit cost, the other element of the tax administration's budget.

The remainder of this paper is organized as follows. Next section describes the model and shows the optimal fiscal policy under full information. Section 3 analyzes the optimal fiscal policy under asymmetric information. Section 4 presents the numerical results of our model and highlights the differences with respect to those obtained in a model without investment in the tax administration. Finally, Section 5 concludes. All proofs appear in the Appendix.

\section{The model}

We formalize the design and the implementation of a fiscal policy in a simple three-stage model, with two classes of active agents: a government and individuals.

There is a continuum of individuals of measure 1. Each individual can be of two different types $\iota \in\{p, r\}$. A 'poor' individual $(\iota=p)$ has no income whereas a 'rich' individual $(\iota=r)$ earns a strictly positive taxable income $y$. Types are random variables,

\footnotetext{
${ }^{7}$ In Mayshar's (1991) words, these reduced-form functions are 'black boxes'.
} 
identically and independently distributed according to the (commonly known) probability distribution $(\mu, 1-\mu)$, where $\mu=\operatorname{Pr}[\iota=r]>0 .{ }^{8}$ Each individual privately knows his type.

Poor individuals only benefit from a public good, provided by the government, in quantity $G$. Their ex-post welfare is given by

$$
w_{p}=G .
$$

Rich individuals also derive utility from consumption of a private good $q$, the price of which is normalized to 1 . So their ex-post welfare is

$$
w_{r}=u(q)+G
$$

where the utility function $u$ is strictly increasing, concave and verifies the Inada conditions. ${ }^{9}$

The government follows a welfarist criterion $\mathcal{W}$ that can be represented by a weighted sum of the individuals' welfares, as follows

$$
\begin{aligned}
\mathcal{W} & =\mu w_{r}+(1-\mu) w_{p}-\mu(1-\alpha)\left(w_{r}-w_{p}\right) \\
& =\alpha \mu u(q)+G
\end{aligned}
$$

where $0 \leq \alpha \leq 1$ is a parameter that measures preferences for redistribution. ${ }^{10}$ To be more specific, the government is averse to inequality, with a degree of aversion proportional to $(1-\alpha)$. In order to maximize its criterion, the government designs a fiscal policy, to be implemented by the tax administration.

The order of events, and relevant features of the model in more detail, are as follows.

1. In the first stage, the government invests $I$ to 'modernize' the tax administration.

2. In the second stage, the government designs the tax law, which specifies the tax $t \geq 0$ owed by rich individuals (from now on, taxpayers) and the enforcement policy to be conducted afterwards by the tax administration. The enforcement policy consists specifically of an audit probability $\pi \in[0,1]$ and a fine for evaders $f \geq 0$. The unique restriction to this tax law is limited liability of taxpayers.

3. In the third stage, the tax law is implemented. As the tax administration does not observe types $\iota$, individuals are requested to report them, e.g. by filling in an income tax form. We denote such reports by $\widetilde{\imath}$. Then, following the enforcement policy

\footnotetext{
${ }^{8}$ Measurability issues arise in probability spaces with a continuum of iid random variables, as it is the case in our setting. In spite of this, we will adopt throughout the paper the usual abuse of the Law of Large Numbers. Hence $\mu$ also represents the proportion of rich individuals in the population.

${ }^{9}$ Utilities that are linear in the public good have been recently adopted in the public economics literature. For example, Ray and Vohra (2001) and Bloch and Zenginobuz (2006) use them in models of public goods provision, albeit in other contexts.

${ }^{10}$ This social welfare function has been studied theoretically by Ledyard and Palfrey (1999), and used, in a more applied context, by Laffont and Martimort (2005). This criterion is especially interesting because, as $\alpha$ adopts values between 0 and 1, it describes a family of standardly used social welfare functions. In particular, when $\alpha=0$, the social welfare function is Rawlsian; whereas, when $\alpha=1$, it is utilitarian.
} 
previously designed by the government, the tax administration audits each report $\widetilde{\iota}$ with probability $\pi_{\widetilde{\iota}}$.

Each audit costs $C=c(I, \delta) \geq 0$, where $\delta$ is a positive parameter. Let $C_{0}=c(0, \delta)$ denote the initial audit cost, before an investment decision has been made. This level $C_{0}$ is an exogenous function of the stock of capital the tax administration is endowed with at the beginning of the first stage and/or other exogenous parameters that are related to the difficulty in auditing (e.g. the percentage of farmers in the population). ${ }^{11}$ The main assumption of the paper is the following: the audit cost decreases with investment $I$, at a decreasing rate. This is precisely the meaning that the expression 'modernization of the tax administration' has in our paper. Formally, the audit cost function $c$ verifies ${ }^{12}$

$$
c_{I}<0, c_{I I}>0 \text { and } \lim _{I \rightarrow \infty} C=0
$$

The cost function $c$ also verifies that the higher the parameter $\delta$, the higher the capacity of any level of investment to reduce the initial audit cost: $c_{\delta}<0$. This is why we call $\delta$ the 'investment productivity'.

When a taxpayer is not audited, he pays the tax that corresponds to his report $\widetilde{\iota} .^{13}$ But if he is audited, the tax administration discovers his true type $\iota$. And, if a misreport is detected, the evader has to pay the tax that he legally owes plus the additional fine $f .{ }^{14}$ With all revenues collected (taxes and fines, net of investment and audit costs), the government finances the provision of the public good $G$, which has a unit cost equal to $p$.

The assumptions of the model and its timing deserve some comments.

To simplify the model ${ }^{15}$, we assume that the government makes all the decisions. The tax administration is simply a 'machine' that follows the government's directives, unlike in Cremer, Marchand and Pestieau (1990) and in Sanchez and Sobel (1993), where the tax administration decides the audit strategy. In spite of this, and for the sake of realism, we follow these authors in separating (only formally) the tax administration from the government.

Regarding full commitment to the enforcement policy, this assumption generates a framework where, a priori, investments have the lowest value (i.e. they do not have a commitment value). We could have adopted two other assumptions: partial commitment (see Melumad and Mookherjee 1989) or no commitment (see Graetz, Reinganum and Wilde 1986). These other assumptions, although more realistic, do not enrich the model substantially. In fact, they unnecessarily complicate the computations, without modifying

\footnotetext{
${ }^{11}$ It is well known that auditing income generated in agricultural activities is very difficult, either in developed or developing countries.

${ }^{12}$ Throughout the paper, subscripts of functions denote partial derivatives.

${ }^{13}$ For the sake of simplicity, we assume that tax collection is costless, both for taxpayers and for the tax administration.

${ }^{14}$ Like Marhuenda and Ortuño-Ortín (1997), we rule out of the model rewards for truthful reports.

${ }^{15}$ Vakneen and Yitzhaki (1989) comment on the necessity of simplifying this kind of problems.
} 
qualitatively the main results regarding the optimality of investing to modernize the tax administration.

Concerning the investment decision, two observations can be made. First, and related to the previous comment, the fact that the government chooses the investment's level replicates the US Congress creating an special account for the IRS, with funds to be used only for the modernization of the IRS's information technology. Second, the lag between the investment decision and then the design of the tax law is clearly a shortcut, reflecting the long-term character of these investments (made once, with an impact that carries over many years) with respect of the sort-term of the tax law (designed yearly).

The reason for assuming that the government taxes only the rich and that individual welfares are quasi-linear in the public good is purely technical. The first assumption enables us to obtain necessary and sufficient conditions to characterize the optimal tax law analytically. ${ }^{16}$ In the next section, we explain why this assumption is not, in fact, so restrictive. The second assumption is sufficient to guarantee non-ambiguous signs in the comparative statics analysis at the second stage. In turn, all this is necessary to obtain any result regarding the optimal level of investment, at the first stage.

Finally, we do not follow the literature that considers that 'the punishment should fit the crime'. In our model, the government can choose any fine, with no restriction other than limited liability. This rules out of the model the beckerian-type result 'hanging evaders with probability zero'.

The goal of the paper is to characterize the optimal fiscal policy, which is the 4 -uple $\left\{I, t, f, \pi_{\tau}\right\}$. Before doing that, and in order to have a benchmark, we present the optimal fiscal policy under full information. In this case, the tax administration observes incomes and thus audits are useless. Anticipating this, the government does not need to invest in the tax administration and simply sets the tax that solves the following problem, where private consumption has been replaced, using the taxpayers' budget constraint, by their disposable income

$$
\mathcal{P}^{*}\left\{\begin{array}{l}
\underset{t, G}{\operatorname{Max}} \quad \alpha \mu u(y-t)+G \\
\text { subject to } \\
0 \leq t \\
t \leq y \\
p G=\mu t
\end{array}\right.
$$

We denote by $(L L)$ the limited liability constraint and by $(B)$, the government's budget constraint. The following expressions

$$
\begin{array}{ll}
\alpha u_{q}\left(y-t^{*}\right)=\frac{1}{p} & \text { if } t^{*}>0 \\
\alpha u_{q}(y)>\frac{1}{p} & \text { otherwise }
\end{array}
$$

\footnotetext{
${ }^{16}$ In more general models, Cremer, Marchand and Pestieau (1990) and Pestieau, Possen and Slutsky (2004) have to do numerical simulations to completely characterize the optimal tax law.
} 
characterize the optimal full information tax $t^{*}$. On the one hand, when $u_{q}(y) \leq 1 / \alpha p$, the government taxes the rich in order to equalize their social marginal utility of consumption with the social marginal utility of the last $\$$ spent in the public good. On the other hand, when $u_{q}(y)>1 / \alpha p$, taxation is too costly in welfare terms and thus $t^{*}=0$. We denote by $G^{*}=\mu t^{*} / p$ the optimal provision of public good.

\section{Optimal fiscal policy under asymmetric information}

In this section, we characterize the optimal fiscal policy under asymmetric information, when the tax administration can only observe incomes at a cost, by auditing reports. In order to do this, we solve the model backwardly.

\subsection{The optimal tax law}

The government can commit to the audit probability $\pi_{\widetilde{\iota}}$ when it designs the tax law; thus, the Revelation Principle applies. Hence, the optimal tax law can be easily characterized adopting a mechanism design approach. According to Mookherjee and Png (1989), the tax administration does not need to audit a taxpayer that has reported to be rich. From now on, $\pi$ will denote the probability of auditing an announcement $\widetilde{\iota}=p$. The optimal tax law $(t, f, \pi)$ solves the following problem, where again private consumptions have been replaced by taxpayers' disposable income, but now at each possible final state.

$$
\mathcal{P}_{1} \begin{cases}\underset{t, f, \pi, G}{\operatorname{Max}} \alpha \mu u(y-t)+G \\ \text { subject to } \\ 0 \leq t \\ t+f \leq y \\ u(y-t) \geq \pi u(y-t-f)+(1-\pi) u(y) & (I C) \\ p G=\mu t-(1-\mu) \pi C-I & \left(L^{\prime}\right)\end{cases}
$$

Now we denote by $\left(L L^{\prime}\right)$ the after audit limited liability constraint ${ }^{17}$ and by $(I C)$, the incentive compatibility constraint. ${ }^{18}$ With respect to the full information setting, the government's budget constraint $\left(B^{\prime}\right)$ now incorporates the aggregate audit cost $(1-\mu) \pi C$ and the investment $I .{ }^{19}$ As it is usual in this kind of models, the fine $f$ does not enter in the maximand of the problem $\mathcal{P}_{1}$ because it has only a deterrent role.

\footnotetext{
${ }^{17}$ As $f \geq 0$, imposing after audit limited liability constraint also ensures $t \leq y$.

${ }^{18}$ Since the number of taxpayers is very large, none of them considers the impact of their non-compliance with the tax law on the amount of public good. So the public good does not appear in the incentivecompatibility constraint.

${ }^{19}$ Without any loss of generality, we do not impose the net tax collection to be (weakly) positive because this should hold at the optimum. If this were not the case, it is straightforward to realize that not investing in the tax administration or not taxing the rich (and thus not enforcing the tax law) would dominate, making the net tax collection to be in fact (weakly) positive.
} 
At the optimum, $\left(L L^{\prime}\right)$ binds: increasing the fine $f$ up to its maximal legal level $y-t$ relaxes $(I C)$. Moreover, as in other Principal-Agent models of tax-enforcement policies, e.g. Mookherjee and Png (1989), (IC) also binds. The government sets an audit strategy

$$
\pi=1-\frac{u(y-t)}{u(y)}
$$

such that a potential evader is indifferent between truthfully reporting his type and misreporting. Computing the first-order condition of the problem $\mathcal{P}_{1}$ and rearranging, we obtain the expression that characterizes the optimal tax at an interior solution

$$
\alpha u_{q}(y-t)=\frac{1}{p}\left[1-\frac{(1-\mu) C}{(1-\mu) C+\alpha \mu p u(y)}\right]
$$

Under asymmetric information, the taxpayers' social marginal utility of consumption again equals the social marginal utility of the expenditure in the public good. Now, due to the necessity of auditing reports in order to collect taxes, this expenditure is less than the tax collection. Therefore, by concavity of the utility function $u$, the optimal tax $t$ is downwardly distorted with respect to the optimal full information tax $t^{*}$. We gather these results in the next proposition, where we completely characterize the optimal tax and audit probability. In particular, we explain in detail how the solutions vary with the audit $\operatorname{cost} C$ because this will be useful in the next section.

Proposition 1 Let $\bar{C}=\frac{\left[1-\alpha p u_{q}(y)\right] \mu u(y)}{(1-\mu) u_{q}(y)}$. Under asymmetric information, the following two regimes emerge.

- Regime $R^{A}:$ when $C<\bar{C}$, the optimal tax $t$ and the optimal audit probability $\pi$ are continuous and strictly decreasing functions of $C$ that satisfy

$$
\lim _{C \rightarrow 0} t=t^{*} \quad, \quad \lim _{C \rightarrow \bar{C}} t=0
$$

and

$$
\lim _{C \rightarrow 0} \pi=\pi^{M a x}=1-\frac{u\left(y-t^{*}\right)}{u(y)} \quad, \quad \lim _{C \rightarrow \bar{C}} \pi=0 .
$$

- Regime $R^{N A}$ : when $C \geq \bar{C}$, the government does not tax and the tax administration does not audit.

Under regime $R^{A}$, the optimal tax is below $t^{*}$ and decreases with the audit cost $C$. In order to understand why, let's assume first that $C=0$. The government sets the full information optimal tax $t^{*}$, charges the tax administration to audit with probability $\pi^{\text {Max }}$ and to punish evaders with the fine $f=y-t^{*}$. Now consider an increase in the audit cost $C$. This makes the aggregate audit cost $(1-\mu) \pi C$ to increase, causing a decrease in the provision of the public good, with its consequent welfare loss. What should be the optimal reaction of the government? To reduce the tax $t$ and to increase the fine $f$, while keeping their sum constant, equal to $y$. Even if this change reduces the tax collection and, a priori, 
decreases further the provision of the public good, it has two other effects that attenuate the above mentioned welfare loss. First, the decrease in $t$ reduces the stake for evasion. Therefore, $\pi$ can decrease from $\pi^{M a x}$, countering the impact of the initial increase in $C$ on the aggregate audit cost. Second, reducing the tax makes private consumption of the rich to increase. A similar argument can be used to explain why the distortion $t^{*}-t$ increases with the audit $\operatorname{cost} C$.

This is not the end of the story. For a 'sufficiently high' value of the audit cost $C$, namely $\bar{C}$, the optimal tax $t$ converges to 0 . Then, when $C \geq \bar{C}$, regime $R^{N A}$ emerges: the audit cost is so high that enforcement is prohibitive, thus $\pi=0$. Under this regime, the unique incentive-compatible tax is 0 and the fine is irrelevant. So, no redistribution takes place.

These results are similar to those obtained by Pestieau, Possen and Slutsky (2004). Besides the optimality of maximal fines and the characterization of the optimal audit probability from the binding incentive-compatibility constraint, we find the same regimes ${ }^{20}$ and we confirm analytically their numerical comparative statics results (see their Table 1, page 351). Therefore, as our model qualitatively replicates the optimal tax law found in their more general setting, our assumption regarding not taxing the poor does not seem to be so restrictive as one could have initially thought.

Finally, the optimal provision of public good $G$ is also a continuous and strictly decreasing function of $C$ that satisfy

$$
\lim _{C \rightarrow 0} G=G^{*} \text { and } \lim _{C \rightarrow \bar{C}} G=0 .
$$

When tax evasion is an issue, the provision of public good $G$ is below the full information level $G^{*}$. Falkinger (1991) does not find such a clear-cut result because his model is more general.

\subsection{The optimal investment}

In the first stage, anticipating its future fiscal choices, the government chooses whether to invest to modernize its tax administration and, if so, how much to invest. This decision has two different impacts. On the one hand, it affects the expected social welfare because the government allocates tax revenues to investment $I$ instead of allocating them to the public good $G$. On the other hand, as investment changes the value of the audit cost $C$, this decision can also fix under which regime the government will design the tax law and the tax administration will operate. In order to address the choice of regime in terms of the variable $I$, let $\bar{I}$ denote the solution of the implicit equation $c(I, \delta)=\bar{C} \cdot{ }^{21}$ Thus, the

\footnotetext{
${ }^{20}$ Unlike Pestieau, Possen and Slutsky (2004), we have to derive a formal expression of the threshold $\bar{C}$ because it will play a crucial role in the analysis of the first stage of the model.

${ }^{21}$ Due to the properties of the cost function $c, \bar{I}$ is unique.
} 
expected welfare can now be written as a function of investment $I$, as follows

$$
\begin{aligned}
& \text { if } C_{0} \leq \bar{C} \quad \mathbb{E} \mathcal{W}=\mathbb{E}_{\mathcal{W}} \mathcal{W}^{A}=\alpha \mu u(y-t)+\frac{1}{p}[\mu t-(1-\mu) \pi C-I] \\
& \text { if } C_{0}>\bar{C} \quad \mathbb{E} \mathcal{W}= \begin{cases}\mathbb{E} \mathcal{W}^{N A}=\alpha \mu u(y) & \text { for } I \geq 0 \\
\mathbb{E} \mathcal{W}^{A}=\alpha \mu u(y-t)+\frac{1}{p}[\mu t-(1-\mu) \pi C-I] & \text { if } I \geq \bar{I}>0\end{cases}
\end{aligned}
$$

where the superscripts indicate the corresponding regime. The expression of $\mathbb{E} \mathcal{W}^{N A}$ takes into account that, as the government raises no tax revenues, investment in the tax administration cannot be afforded. As we can see, the value of the initial audit cost $C_{0}$ is now important to characterize the expected welfare. When $C_{0} \leq \bar{C}$, only regime $R^{A}$ emerges because, no matter the investment decision, $C \leq \bar{C}$. This is not the case when $C_{0}>\bar{C}$ : according to the value of the investment, both regimes $R^{N A}$ or $R^{A}$ can occur.

In order to solve for the optimal investment, we proceed as follows. First, we find the investment that maximizes $\mathbb{E} \mathcal{W}^{A}$. If it exists, we denote it by $I_{A}$. Second, when it is pertinent to do so, we compare $\mathbb{E} \mathcal{W}^{A}\left(I_{A}\right)$ with $\mathbb{E} \mathcal{W}^{N A}$ to take the overall maximum.

Under regime $R^{A}$, the optimal investment $I_{A}$ is the solution to the following problem

$$
\mathcal{P}_{2}\left\{\begin{array}{l}
\underset{I}{M_{I}} \quad \alpha \mu u(y-t)+\frac{1}{p}[\mu t-(1-\mu) \pi C-I] \\
\text { subject to } \\
t=t(C), \pi=\pi(C)=1-\frac{u(y-t(C))}{u(y)} \\
C=c(I, \delta) \\
\max \{0, \bar{I}\} \leq I \\
I \leq \mu t-(1-\mu) \pi C
\end{array}\right.
$$

where $t(C)$ and $\pi(C)$ are the solutions to the problem $\mathcal{P}_{1}$. From Proposition 1 , they are uniquely defined and continuous decreasing functions of the audit cost $C$. The last two inequalities characterize the constraint set. The first inequality reflects that the lowest value of $I$ supporting regime $R^{A}$ is not unique because it depends upon the initial audit $\operatorname{cost} C_{0}$, as it is clear from (3). The second inequality shows the resource constraint of the government, at this initial stage.

A general characterization of the solution to $\mathcal{P}_{2}$ is difficult, for the following reasons. First, when $\max \{0, \bar{I}\}=\bar{I}$, the constraint set may be empty. Indeed, under some parameter configurations [e.g. high initial audit cost $C_{0}$ and low investment productivity $\delta$ ], no investment fulfills the resource constraint. Second, even if the constraint set is non-empty and we can prove that the problem $\mathcal{P}_{2}$ has a maximum, it is often difficult to find it with the usual techniques because the expected welfare $\mathbb{E} \mathcal{W}^{A}$ is not always concave in $I$ and the second-order condition, evaluated at the critical points, cannot be verified analytically. ${ }^{22}$

\footnotetext{
${ }^{22}$ Investment $I$ impacts the expected welfare $\mathbb{E} \mathcal{W}^{A}$ in many different ways: (i) directly: through the
} 
Finally, even if one succeeds in identifying $I_{A}$, the comparison between $\mathbb{E} \mathcal{W}^{N A}$ and $\mathbb{E} \mathcal{W}^{A}\left(I_{A}\right)$ is not straightforward because it is a comparison of levels. All these difficulties ${ }^{23}$ push us to simulate the model in the next section.

But before doing that, we can prove the following results that apply when the optimal investment $I>0$.

Proposition 2 If the government invests a strictly positive amount of money to modernize its tax administration, the optimal tax $t$, the optimal audit probability $\pi$ and the level of public good $G$ are higher with respect to their level in a model without investment.

If the optimal investment is strictly positive, each audit costs less than $C_{0}$. Therefore, by Proposition 1, the optimal tax and the optimal audit probability increase with respect to their level in a model without investment. Intuitively, one could also expect the result about $G$. However, this intuition must not be based on the simple observation that investment reduces audit cost and thus, ceteris paribus, $G$ increases. The point is that, as $t$ increases when investment is realized, optimality implies that the provision of the public good must increase, to compensate for the lower consumption of taxpayers. Next, we present some comparative statics results.

Proposition 3 If the government invests a strictly positive amount of money to modernize its tax administration, the optimal investment I increases with taxable income $y$ and with the degree of aversion to inequality $(1-\alpha)$, but decreases with the cost of the public good $p$. With respect to the other parameters of the model, the change in the optimal investment I is ambiguous.

An optimal investment $I>0$ is characterized by the following expression

$$
-(1-\mu) \pi c_{I}=1
$$

where the lhs of (4) is the marginal saving in the aggregate audit cost (hereinafter MSAAC) and the rhs, the marginal cost of investment (hereinafter MCI), which is always 1. From (4), we can realize that the total effect on the optimal investment of a change in one parameter is the result from the combination of two potential effects on the MSAAC. First, there is a direct effect that occurs when this parameter change affects only $(1-\mu), \pi$ or $c_{I}$. Second, there is an indirect effect provided this parameter change causes a variation in the optimal tax $t$, making also the optimal audit probability $\pi$ to change. So, if after a change in one parameter the MSAAC is greater (lesser) than the MCI, the government restores optimality by increasing (decreasing) the investment. Having this in mind, we explain in detail the comparative statics results presented in the proposition.

budget constraint of the government, and (ii) indirectly: through $C$ (whose degree of convexity depends upon the retained functional specification for the relation $C(I, \delta))$ and through the optimal values of $t$ and $\pi$ (whose concavity or convexity in $I$ depends upon the third derivative $u_{q q q}$ ). But, as there are no convincing arguments (neither theoretical nor empirical) for either the form of $C(I, \delta)$ or the sign of $u_{q q q}$, the concavity of the expected welfare $\mathbb{E} \mathcal{W}^{A}$ is, in fact, a numerical question. Hence, we can always find functional specifications of $C(I, \delta)$ and $u$ such that $\mathbb{E} \mathcal{W}^{A}$ is not concave in $I$, as Figure 1 depicts (see below).

${ }^{23}$ Illustrations of these technical difficulties can be obtained upon request from the authors. 
- When taxable income $y$ increases, the two effects have opposite signs. On the one hand, the direct effect in $\pi$ is negative. The intuition for this result is as follows. For a given tax $t$, the stake for evasion (i.e. the gain $u(y)-u(y-t))$ decreases when $y$ increases, due to the concavity of the utility function $u$. Therefore, in order to ensure incentive compatibility, it is not necesary to audit so much, and thus the optimal audit probability decreases. On the other hand, the indirect effect is positive: an increase in $y$ enables the government to tax more and thus $\pi$ increases. In spite of this, the indirect effect dominates and thus $\pi$ increases. As the MSAAC increases, the government optimally invests more.

- When the degree of aversion to inequality $(1-\alpha)$ increases, there is only an indirect effect. Higher aversion to inequality makes the government to increase the tax. This pushes the stake for evasion upwards and so $\pi$ has to increase. As a consequence of this, the MSAAC increases and thus $I$ also optimally increases.

- When the cost of the public good $p$ increases, there is only an indirect effect: the government prefers to tax less. Therefore, the stake for evasion diminishes and thus $\pi$ decreases, leading to a decrease in the MSAAC. So $I$ optimally decreases.

- When either the investment productivity $\delta$ or the initial audit cost $C_{0}$ increase, the two effects may appear. Specifically, in both cases, these effects depend upon the sign and the value of $c_{I \delta}$ and $c_{I C_{0}}$ at the optimum. As there is no justification to assume a priori any sign for these cross derivatives, the result will depend upon the particular specification of the audit cost function $C$.

- Finally, when the fraction of rich individuals in the population $\mu$ increases, the two effects go in opposite directions. On the one hand, the direct effect is clearly negative: when $\mu$ increases, the MSAAC decreases. On the other hand, the indirect effect is positive: an increase in $\mu$ makes the government to tax more. As $t$ increases, so do $\pi$ and the MSAAC. Hence the total effect is ambiguous.

\section{Numerical results}

The numerical simulations of the model $^{24}$ will help us in several ways: to identify parameter configurations under which the optimal investment $I>0$; in this case, to quantify the other components of the optimal fiscal policy and to obtain or confirm the comparative statics results presented in Proposition 3. Throughout these simulations, we adopt the following functional specifications:

- Utility function:

$$
u(x)=\frac{1-\gamma}{\gamma}\left(\frac{x}{1-\gamma}\right)^{\gamma}, \text { with } 0 \leq \gamma \leq 1
$$

\footnotetext{
${ }^{24}$ We did more simulations than those presented here. But, for the sake of conciseness, we prefer to show those whose results add novelty to the discussion. The simulations have been done with Matlab 7.0. All codes and results are available upon request from the authors.
} 
The utility function is assumed to be isoelastic, as in Pestieau, Possen and Slutsky (2004).

- Audit cost function

$$
c(I, \delta)=\frac{C_{0}}{1+\delta I}, \text { with } 0 \leq \delta
$$

This audit cost function generates cross effects (i.e. $c_{I \delta}$ and $c_{I C_{0}}$ are both non null). This enables us to confirm that some of the comparative statics results found in Proposition 3 can be ambiguous.

We also adopt the following baseline parameters

\begin{tabular}{|c|c|c|c|c|c|c|}
\hline$y$ & $\gamma$ & $C_{0}$ & $\delta$ & $1-\alpha$ & $\mu$ & $p$ \\
\hline 100 & 0.5 & 120 & 0.22 & 0.5 & 0.4 & 1 \\
\hline
\end{tabular}

Table 1: Baseline parameters

Before showing the results of the numerical simulations, the next figure illustrates why the value of the optimal investment $I$ can jump. Figure 1 draws, for different levels of the investment productivity $\delta$, the expected welfare $\mathbb{E} \mathcal{W}$ as a function of investment $I$.

\section{Insert Figure 1 here}

When $\delta$ increases, $\mathbb{E} \mathcal{W}$ changes in two different ways. First, the set of values of $I$ that verifies the resource constraint increases. That is the reason why the curves with the two lowest levels of $\delta$ are not defined for all values of $I$. Second, the shape of the curves changes, from a monotonic decreasing curve to a non-monotonic one. The consequence of this change is immediate to see. When $\delta<0.094$, the optimal investment $I=0$. When $\delta=0.094$, two levels of $I$ maximize the expected welfare but then, when $\delta$ increases, the optimal investment $I$ becomes strictly positive. Hence, due to the non-concavity of $\mathbb{E} \mathcal{W}$, the optimal investment can be non-continuos in $\delta$.

The next paragraphs explain in detail, with reference to the corresponding figures, the impact of changes in one parameter on the endogenous variables of the model. Each parameter varies within an interval that contains its baseline level. In the figures, solid curves are obtained when investment is optimally chosen; dashed curves, when investment in the tax administration is not allowed.

\subsection{Change in the investment productivity when $\delta \in[0,2]$}

Given our baseline parameters, $C_{0}=120<\bar{C}=128.62$. Hence, throughout this subsection, only regime $R^{A}$ prevails. Figure 2(a) shows that, when $\delta<0.094$, the investment productivity is so low that it is too costly, in welfare terms, to invest to reduce the initial audit cost $C_{0}$. Only when $\delta=0.094$, the government starts investing: $I$ jumps upward, to 7.94. This figure also confirms one of the ambiguous comparative statics results of Proposition 3: the optimal investment $I$ can be non monotonic in $\delta$. When $\delta \in[0.094,0.18]$, an increase in $\delta$ makes the positive indirect effect to dominate the negative direct effect, 
because, due to the fact that the audit cost is still high, $t$ and $\pi$ can increase a lot in relative terms. So the MSAAC increases above the MCI, implying that $I$ optimally increases. When $\delta=0.18$, the optimal investment $I=10.64$ is maximal. But then, as the investment productivity is sufficiently high, the indirect effect is lower and the negative direct effect starts dominating, making the MSAAC to decrease below the MCI when $\delta$ increases. In other words, it becomes worthless to maintain the increasing profile of investment and so $I$ starts to decrease. This decrease is slow: $\delta$ has to increase more than $1000 \%$ to reduce $I$ by $50 \%$. In Figure 2(b), we can see that the audit cost is initially constant, and then, when $I$ jumps upward, it jumps downward to 68.71. After this point, and despite the nonmonotonicity of $I, C$ monotonically decreases with $\delta$. When $\delta \in[0.094,0.18]$, the combined increases in $\delta$ and $I$ push the audit cost downward. When $\delta>0.18$, the increase in $\delta$ exceeds the decrease in $I$ and thus $C$ continues to decrease, although at a slow rate. At the end, $C$ decreases $83.53 \%$, even more than $I$. In Figure 2(c), we observe that, when $C=C_{0}$, the government sets a low tax $t=12.51$. When $C$ jumps downward, $t$ jumps upward and sharply, to 73.07. Then $t$ monotonically increases 35\%. Similarly, in Figure 2(d), $\pi$ jumps upward at $\delta=0.094$, from 0.065 to 0.48 . Then, $\pi$ monotonically increases $84 \%$, more than the increase in $t$. In Figure 2(e), the aggregate audit cost $A A C$ is initially constant at 4.65, jumps upward to 18.61 and then monotonically decreases, to reach 5.64. From Figures $2(\mathrm{a})$ and $2(\mathrm{e})$, we realize that investment and enforcement expenditures are substitutes when $\delta \in[0.094,0.18]$ and then, when $\delta>0.18$, they are complements. In Figure 2(f), the expenditure in the public good EPG jumps upward at $\delta=0.094$, from 0.35 to 2 , and then monotonically increase, to reach 28.7. Figure $2(\mathrm{~g})$ illustrates the efficiency of the public sector EPS. This percentage measures how much of the tax collection is used to provide public goods. EPS shows an imperceptible downward jump (from $6.99 \%$ to $6.86 \%$ ) and then monotonically increases, to attain $72.67 \%$. Surprisingly, from $\delta=0.094$, the investment productivity $\delta$ has to increase almost $448 \%$ in order to make the expenditure in the public good reach more than $50 \%$ of the expected tax collection.

Insert Figures 2 here

\subsection{Change in the initial audit cost when $C_{0} \in[0,300]$}

In Figure 3(a), when $C_{0}<8$, the initial cost $C_{0}$ is so low that, even under regime $R^{A}$, it does not pay in welfare terms to invest in the tax administration. So the optimal investment $I=0$ and thus the audit cost $C=C_{0}$, which is obviously increasing in this parameter. When $C_{0}=8$, the government starts investing because, as $C_{0}$ is relatively high, the MSAAC is now equal to the MCI. Contrary to the previous simulations, the optimal investment does not jump upward at this point. Then $I$ increases with $C_{0}$, although at a decreasing rate. Thus, the increase in $C_{0}$ dominates the increase in $I$, yielding the audit cost to increase from 0 to 51.6, as we can see in Figure 3(b). But, when $C_{0}=203$, it becomes too expensive, again in welfare terms, to invest to attenuate the increase in the audit cost. Hence, investment vanishes, from its maximum 13.34. This yields an upward jump in the audit cost $C$, from 51.6 to 203. At this point, the audit cost verifies $C>\bar{C}$ and 
thus regime $R^{N A}$ emerges onwards. Figure 3(c) shows that the optimal tax $t$ decreases, from $t^{*}=99.87$ and reaches 82.17 ; and, when $C_{0}=203$, it also vanishes. The optimal audit probability $\pi$ is also decreasing, starting from $\pi^{M a x}=0.965$ and attaining 0.58 , then when $C_{0}=203, \pi$ also jumps downward to 0 . Figure 3(e) shows that the aggregate audit cost increases, to reach 17.88. Clearly, the amount of money spent in the public good decreases with $C_{0}$, from 39.95 , to reach a minimum of 1.64 , at $C_{0}=203$. Figure $3(\mathrm{~g})$ depicts the EPS, which obviously starts at $100 \%$ and then monotonically decreases, to attain $5 \%{ }^{25}$

Insert Figures 3 here

\subsection{Change in the proportion of rich individuals when $\mu \in[0,1]$}

When the proportion of rich individuals $\mu<0.31, \bar{C}$ is very low. Given the baseline parameters $C_{0}$ and $\delta$, a great investment would be necessary to make $C<\bar{C}$. In fact, such an amount of resources is prohibitive, so $I=0$. In other words, there are so many poor that the aggregate audit cost would be very high. Hence, it does not pay to enforce the tax law and thus regime $R^{N A}$ emerges. When $\mu=0.31, I$ jumps upward to 10.09 . As $C$ jumps downward, regime $R^{N A}$ shifts towards regime $R^{A}$. Figure 4 (a) also confirms that the optimal investment $I$ can be non monotonic with respect to $\mu$. From $\mu=0.31, I$ increases with $\mu$. As there are relatively more rich in the population, the government increases the $\operatorname{tax}$ (with the consequent increase in the optimal audit probability $\pi$ ). Hence, the indirect effect offsets the direct effect and so the MSAAC increases, making the government to invest more. When $\mu=0.39$, optimal investment is maximal $(I=10.51)$. Then, if $\mu$ increases, the direct effect starts dominating. As there are fewer poor, the MSAAC decreases below the MCI, making $I$ to monotonically decrease. When $\mu=0.96$, then $I=0$ again. There are almost no poor, so the aggregate audit cost becomes negligible. So does the MSAAC and thus investment is worthless, even under regime $R^{A}$. Concerning the audit cost $C$, it is inversely related to $I$ : first $C$ jumps downward from $C_{0}=120$ to 37.51 , then it decreases slightly to reach 36.22 at $\mu=0.39$ and finally, it increases to attain again $C_{0}$. In Figure $4(\mathrm{c})$, under regime $R^{N A}, t=0$; then $t$ jumps upward to 80.98. After that, the effect of an increase in $\mu$ prevails over the effect through the increase in the audit cost $C$. Hence, $t$ monotonically increases and converges to $t^{*}$. The optimal audit probability $\pi$ behaves similarly in Figure 4(d). First, $\pi$ jumps upward, from 0 to 0.56 ; then it increases to reach $\pi^{M a x}=0.965$. Figure $4(\mathrm{e})$ shows that the aggregate audit cost presents a similar profile than the optimal investment $I$ : it increases from 14.46 to 15.06 and then decreases. The expenditure in the public good monotonically increases, from 0 to the maximum 99.87 when $\mu=1$. Figure $4(\mathrm{~g})$ shows that the EPS increases. ${ }^{26}$

Insert Figures 4 here

\footnotetext{
${ }^{25}$ As there is no tax collection when $C_{0}>203, E P S$ is not defined for such values of the initial audit cost.

${ }^{26}$ As there is no tax collection when $\mu<0.31, E P S$ is not defined for such values of the fraction of rich in the population.
} 


\subsection{Change in taxable income when $y \in[0,200]$}

When taxable income $y<75, \bar{C}$ is very low. So, due to the baseline parameters, it is very likely that $C>\bar{C}$. In other words, the taxable income is so low, with respect to the audit cost, that it does not pay to enforce the tax law and thus regime $R^{N A}$ emerges. In that case, $I=0$. But when $y$ increases, so does $\bar{C}$. Hence, when $y=75$, there is a shift of regimes and the government starts investing in the tax administration: $I$ jumps upward to 8.92. Then $I$ increases with $y$, to reach 12.16 . The indirect effect, which makes the government to increase the tax (with the consequent increase in $\pi$ ) always offsets the direct effect (that makes $\pi$ to decrease). So the MSAAC increases, pushing the government to invest more, albeit slightly. Indeed, from $y=75$, an increase of $166.7 \%$ in taxable income only induces the government to invest $36.3 \%$ more. Concerning the audit cost $C$, it is inversely related to $I$, as we can see in Figure 5(b). First $C$ jumps downward, from $C_{0}=120$ to 40.5 and then it decreases slowly, to attain 32.65. Regarding the optimal tax, only when $y=75$ the government starts taxing the rich $(t=60.08)$. Then, the optimal tax monotonically and sharply increases $388 \%$, converging to $t^{*}$ (which is also increasing in $y$ ). Even if it is difficult to observe directly from Figure 5(c), optimal taxes are indeed progressive, with and without investment. But clearly $t / y$ is higher with investment. In Figure $5(\mathrm{~d}), \pi$ jumps upward from 0 to 0.554 and then monotonically increases, to attain 0.85. The next two figures show the public expenditures. Although the optimal investment increases, the increase in $\pi$ is so important that aggregate audit cost increases $24 \%$. Also, the expenditure in the public good increases with taxable income. Figure 5(g) shows that, despite the fact that the tax collection increases (225\%), the EPS increases, due to the sharp increase in the provision of the public good.

\section{Insert Figures 5 here}

\subsection{Summary of the numerical results}

In this section, we present the main results from the numerical simulations. Figures 3,4 and 5 show that for certain parameter values, regime $R^{A}$ emerges whereas, when investment is absent, the government would not have enforced the tax law.

The simulations also clarify the relation between investment and expenditures in audit. Although investment reduces the cost of each individual audit, it does not necessarily decrease aggregate audit cost as one might expect. First, aggregate audit cost is sometimes higher with investment than without it because regime $R^{A}$ can emerge, instead of regime $R^{N A}$. Second, even when regime $R^{A}$ prevails without investment, $I$ can make $\pi$ to increase too much, increasing aggregate audit cost, as we can see in Figure 2(e). Moreover, despite the fact that investment and aggregate audit cost are complements most of the time, Figures $2(\mathrm{a})$ and $2(\mathrm{e})$ show that they could also be substitutes.

Also, the presence of optimal investment alters some comparative statics results of the

model, in particular those pertaining to the aggregate audit cost, as we can see in Figure $3(\mathrm{e})$. 
Interestingly, the two different ways of modifying the income distribution (i.e. changes in $\mu$ or $y$ ) have not the same impact upon the optimal level of investment. Figure 5(a) confirms that $I$ increases with taxable income, as shown in Proposition 3. But Figure 4(a) shows that, with our baseline parameters, $I$ is non-monotonic when the fraction of rich in the population increases.

All simulations show that, as a consequence of the increase in the provision of the public good, modernizing the tax administration makes the efficiency of the public sector taken as a whole to increase. Again, this is not evident per se because the measure EPS, as defined above, depends not only on the audit cost but also on the other endogenous variables of the model.

Summing up, the simulations confirm that incorporating the modernization of the tax administration in a model of optimal tax-enforcement policies modifies qualitatively its results.

\section{Conclusions}

There is a large list of contributions that have analyzed optimal tax-enforcement policies under the threat of tax evasion. Surprisingly, all assume that the audit cost function is exogenously given. In practice, governments invest many resources to modernize their tax administration and thus, to change audit costs. This paper is a first step towards the incorporation, in the theory of optimal fiscal policies, of these investment decisions. In a very simple model, we have been able to characterize the optimal tax-enforcement policy, adopting a mechanism design approach. As many other contributions to the costlystate verification literature, the optimal fine for evaders is maximal and the optimal audit probability is such that evasion is deterred. However, in order to attenuate the stake for evasion, the government optimally distorts taxes downward, distortion with respect to the full information optimal tax. Then we analyze the optimal investment. Although we prove its existence, we cannot completely characterize the optimal investment in general. When it is strictly positive, the levels of the tax, the audit probability and the public good are higher than their respective levels without investment. Under this circumstance, the optimal investment increases with taxable income and with the degree of aversion to inequality, but decreases with the cost of the public good.

To identify the solutions and to study how the optimal investment interacts with the other components of the optimal fiscal policy, we simulate numerically the model. The simulations clarify the relation between investment and expenditures in audit, showing that, with investment, the aggregate audit cost may be higher than without investment. Moreover, these two endogenous variables of the model can be substitutes or complements. All simulations show that the public sector becomes more efficient with investment: the fraction of tax collection used to provide public goods increases. Summing up, the analythical results of the model and the simulations suggest the need to incorporate the kind of investment analyzed here into the currently definitions of 'tax effort' used in empirical work.

The model can be extended in several directions. First, it could be interesting to consider that the information gathering area of the tax administration faces a more general 
audit cost function, with fixed and variable costs. With such a cost structure, investment can have different impacts (e.g. to increase the fixed cost while decreasing the variable cost). Second, it would be useful to study how the results change if an audit discovers the true income with some probability, probability that is determined by the initial investment. Third, the model can be extended dynamically, to analyze the path of the different elements of the optimal fiscal policy. Fourth, our analysis can be generalized to incorporate more than two levels of income or more dimensions of heterogeneity (e.g., different degrees of risk aversion). Then one could think to calibrate an optimal tax-enforcement model with empirically founded parameters, and then to proceed by adding investments to modernize the tax administration into the simulations. Finally, the model generates some testable implications. All these are interesting venues for future research.

\section{References}

ALLINGHAM, M., and A. SANDMO (1972) Income Tax Evasion: A Theoretical Analysis, Journal of Public Economics 1, 323-338.

ALM, J. (1996) What is an 'Optimal Tax System'?, National Tax Journal 49, 117-133.

BALESTRINO, A., and U. GALMARINI (2003) Imperfect Tax Compliance and the Optimal Provision of Public Goods, Bulletin of Economic Research 55, 37-52.

BERGE, C. (1963) Topological Spaces. New York: Macmillan.

BLOCH, F., and U. ZENGINOBUZ (2006) Tiebout equilibria in local public good economies with spillovers, Journal of Public Economics 90, 1745-1763.

BORDER, K., and J. SOBEL (1987) Samourai Accountant: A Theory of Auditing and Plunder, Review of Economic Studies 54, 525-540.

CHANDER, P., and L. WILDE (1998) A General Characterization of Optimal Income Tax Enforcement, Review of Economic Studies 65, 165-183.

COWELL, F. (1985) The Economic Analysis of Tax Evasion, Bulletin of Economic Research 37, 163-193.

CREMER, H., and F. GAHVARI (1994) Tax Evasion, Concealment and the Optimal Linear Income Tax, Scandinavian Journal of Economics 96, 219-239.

CREMER, H., and F. GAHVARI (1995) Tax evasion and the optimum general income tax, Journal of Public Economics 60, 235-249.

CREMER, H., M. MARCHAND and P. PESTIEAU (1990) Evading, Auditing and Taxing The Equity-Efficiency Tradeoff, Journal of Public Economics 43, 67-92.

FALKINGER, J. (1991) On optimal public good provision with tax evasion, Journal of Public Economics 45, 127-133.

GOTTLIEB, D. (1985) Tax evasion and the Prisoner's Dilemma, Mathematical Social Sciences 10, 81-89. 
GRAETZ, M., J. REINGANUM and L. WILDE (1986) The Tax Compliance Game: Toward an Interactive Theory of Law Enforcement, Journal of Law, Economics and Organization 2, 1-32.

HUNTER, W., and M. NELSON (1996) An IRS production function, National Tax Journal 49, 105-115.

IRS (2000) IRS Organization Blueprint, Document 11052 (Rev. 4-2000).

IRS (2005) "Strategic Plan 2005-2009," IRS Publication \#3744.

IRS (2006) "IRS Updates Tax Gap Estimates," IRS-2006-28.

KAPLOW, L. (1990) Optimal Taxation with Costly Enforcement and Evasion, Journal of Public Economics 43, 221-236.

KOLM, S. (1973) A Note on Optimum Tax Evasion, Journal of Public Economics 2, 265270.

LAFFONT, J.-J., and D. MARTIMORT (2005) The Design of Transnational Public Good Mechanisms for Developing Countries, Journal of Public Economics 89, 159-196.

LEDYARD, J., and T. PALFREY (1999) A Characterization of Interim Efficiency with Public Goods, Econometrica 67, 435-448.

MARHUENDA, F., and I. ORTUÑO-ORTÍN (1997) Tax Enforcement Problems, Scandinavian Journal of Economics 99, 61-72.

MAYSHAR, J. (1991) Taxation with Costly Administration, Scandinavian Journal of Economics 93, 75-88.

MELUMAD, N., and D. MOOKHERJEE (1989) Delegation as commitment: the case of income tax audits, RAND Journal of Economics 20, 139-163.

MOOKHERJEE, D. and I. PNG (1989) Optimal Auditing, Insurance and Redistribution, The Quarterly Journal of Economics 104, 399-415.

PESTIEAU, P., U. POSSEN and S. SLUTSKY (1994) Optimal Differential Taxes and Penalties, Public Finance 49, 15-27.

PESTIEAU, P., U. POSSEN and S. SLUTSKY (2004) Jointly Optimal Taxes and Enforcement Policies in Response to Tax Evasion, Journal of Public Economic Theory 6, 337-374.

RAY, D., and R. VOHRA (2001) Coalitional Power and Public Goods, Journal of Political Economy 109, 1355-1384.

SANCHEZ, I., and J. SOBEL (1993) Hierachical design and enforcement of income tax policies, Journal of Public Economics 50, 345-369.

SANDMO, A. (1981) Income Tax Evasion, Labour Supply and the Equity-Efficiency TradeOff, Journal of Public Economics 16, 265-288.

SKINNER, J., and J. SLEMROD (1985) An Economic Perspective on Tax Evasion, National Tax Journal 38, 345-353. 
SLEMROD, J. (1990) Optimal Taxation and Optimal Tax Systems, Journal of Economic Perspectives 4, 157-178.

SLEMROD, J. (1994) Fixing the leak in Okun's bucket Optimal tax progressivity when avoidance can be controlled, Journal of Public Economics 55, 41-51.

SLEMROD, J., and W. KOPCZUK (2002) The optimal elasticity of taxable income, Journal of Public Economics 84, 91-112.

SLEMROD, J., and S. YITZHAKI (1987) The Optimal Size of a Tax Collection Agency, Scandinavian Journal of Economics 89, 183-192.

SLEMROD, J., and S. YITZHAKI (2002) Tax Avoidance, Evasion, and Administration, in Handbook of Public Economics, Vol. 3, A. Auerbach and M. Feldstein, eds. Amsterdam: Elsevier.

SNAVELY, K. (1988) Innovations in State Tax Administrations, Public Administration Review 48, 903-910.

TAKAYAMA, A. (1985) Mathematical Economics.Cambridge: Cambridge University Press. THE PRESIDENT'S COMMISSION TO STUDY CAPITAL BUDGETING (1998) Internal Revenue Service (IRS) Modernization, Staff Paper.

TIROLE, J. (1988) The Theory of Industrial Organization. Cambridge: The MIT Press.

US GENERAL ACCOUNTING OFFICE (1999) Uses of and Problems with IRS's NonMaster File, GAO/CGD-99-42.

USHER, D. (1986) Tax evasion and the marginal cost of public funds, Economic Inquiry 24, 563-586.

VAKNEEN, Y., and S. YITZHAKI (1989) The Shadow Price of a Tax Inspector, Public Finance 44, 492-505.

VARON, E. (2004) For the IRS there's no Ez Fix, CIO, April.

WERTZ, K. (1979) Allocation by and output of a tax-administering agency, National Tax Journal 32, 143-157. 


\section{Appendix}

Characterization of the optimal tax law $(t, f, \pi)$

$\underline{\text { First-order condition }}$

Formally, the government solves the following problem

$$
\mathcal{P}_{1} \begin{cases}\underset{t, f, \pi, G}{M a x} \quad \alpha \mu u(y-t)+G \\ \text { subject to } \\ 0 \leq t \\ t+f \leq y \\ u(y-t) \geq \pi u(y-t-f)+(1-\pi) u(y) \quad(I C) \\ p G=\mu t-(1-\mu) \pi C-I\end{cases}
$$

At the optimum, $\left(L L^{\prime}\right)$ binds: increasing the fine $f$ up to its maximal legal level relaxes the incentive compatibility constraint, with no other impact in the aggregate welfare. Moreover, as it is usual in Principal-Agent models of tax enforcement-policies like Mookherjee and Png (1989), (IC) also binds: the government sets an audit strategy that makes a potential evader to be indifferent between truthfully reporting his type and misreporting. From this binding constraint and replacing $f$ by $y-t$, we can obtain the value of the optimal audit probability, as follows

$$
\pi=1-\frac{u(y-t)}{u(y)}
$$

Moreover, we can also obtain the value of $G$ from $\left(B^{\prime}\right)$. So, replacing $\pi$ and $G$, the maximand of $\mathcal{P}_{1}$ becomes

$$
\alpha \mu u(y-t)+\frac{1}{p}\left(\mu t-(1-\mu)\left[1-\frac{u(y-t)}{u(y)}\right] C-I\right)
$$

which is a strictly concave function of $t .^{27}$

Differentiating (5) with respect to $t$, we obtain the necessary and sufficient first-order condition that characterizes an interior optimal tax $t$, as follows

$$
\alpha u_{q}(y-t)=\frac{1}{p}\left[1-\frac{(1-\mu) C}{(1-\mu) C+\alpha \mu p u(y)}\right]
$$

By strict concavity of (5), the optimal tax is unique. Moreover, as the utility function $u$ is concave, the optimal tax verifies $t \leq t^{*}$.

\footnotetext{
${ }^{27}$ Indeed, the second derivative of (5) with respect to $t$ is

$$
u_{q q}(y-t)\left(\alpha \mu+\frac{(1-\mu) C}{\mu u(y)}\right)<0
$$
}




\section{Comparative statics}

By the Maximum theorem (see Berge 1963), the optimal tax $t$ is a continuous function of $C$, and so are $\pi$ and $f$. In order to completely characterize the optimal tax law $(t, f, \pi)$, let's compute $\frac{\partial t}{\partial C}$. From (6), we can apply the Implicit Function theorem and show that

$$
\begin{gathered}
\frac{\partial t}{\partial C}=\frac{\mu(1-\mu) u(y)}{S}<0 \quad \frac{\partial \pi}{\partial C}=\frac{\partial \pi}{\partial t} \frac{\partial t}{\partial C}=\frac{u_{q}(y-t)}{u(y)} \frac{\partial t}{\partial C}<0 \\
\frac{\partial G}{\partial C}=\left(\frac{\alpha \mu^{2} p u(y)}{(1-\mu) C+\alpha \mu p u(y)}\right) \frac{\partial t}{\partial C}-(1-\mu)<0
\end{gathered}
$$

where $S=u_{q q}(y-t) \cdot[(1-\mu) C+\alpha \mu p u(y)]^{2}$. We can also compute ${ }^{28}$

$$
\begin{array}{cc}
\frac{\partial t}{\partial \alpha}=\frac{p[\mu u(y)]^{2}}{S}<0 & \frac{\partial \pi}{\partial \alpha}=\frac{\partial \pi}{\partial t} \frac{\partial t}{\partial \alpha}<0 \\
\frac{\partial t}{\partial \mu}=\frac{-u(y) C}{S}>0 & \frac{\partial \pi}{\partial \mu}=\frac{\partial \pi}{\partial t} \frac{\partial t}{\partial \mu}>0 \\
\frac{\partial t}{\partial y}=\frac{-1}{u_{q q}(y-t)}\left[\frac{\mu(1-\mu) u_{q}(y) C}{[(1-\mu) C+\alpha \mu p u(y)]^{2}}-u_{q q}(y-t)\right]>0 \\
\frac{d \pi}{d y}=\frac{\partial \pi}{\partial y}+\frac{\partial \pi}{\partial t} \frac{\partial t}{\partial y}=\frac{-u_{q}(y-t)}{u(y)} \frac{\mu(1-\mu) u_{q}(y) C}{S}+\frac{u(y-t) u_{q}(y)}{[u(y)]^{2}}>0 \\
\frac{\partial t}{\partial p}=\frac{\alpha[\mu u(y)]^{2}}{S}<0 & \frac{d \pi}{d p}=\frac{\partial \pi}{\partial t} \frac{\partial t}{\partial p}<0
\end{array}
$$

\section{Domain of positive taxation}

Let's find the parametric region (with respect to the audit $\operatorname{cost} C$ ) where $t \geq 0$. From (6), we can find the value $\bar{C}$ that generates the limit case $t=0$. This value is implicitly characterized by the following expression

$$
\alpha u_{q}(y)=\frac{1}{p}\left[1-\frac{(1-\mu) C}{(1-\mu) C+\alpha \mu p u(y)}\right]
$$

After some manipulations, we obtain

$$
\bar{C}=\frac{\left[1-\alpha p u_{q}(y)\right] \mu u(y)}{(1-\mu) u_{q}(y)}
$$

\footnotetext{
${ }^{28}$ The effects of the parametric changes on $f$ have the opposite signs than the analyzed effects on $t$.
} 
Finally, with all these results, we can easily derive that $\lim _{C \rightarrow 0} t=t^{*}$ and $\lim _{C \rightarrow \bar{C}} t=0$. Moreover, it is straightforward to see that

$$
\begin{aligned}
& \lim _{C \rightarrow 0} f=y-t^{*} \text { and } \lim _{C \rightarrow \bar{C}} f=0 \\
& \lim _{C \rightarrow 0} \pi=\pi^{M a x} \equiv 1-\frac{u\left(y-t^{*}\right)}{u(y)} \text { and } \lim _{C \rightarrow \bar{C}} \pi=0 \\
& \lim _{C \rightarrow 0} G=G^{*} \text { and } \lim _{C \rightarrow \bar{C}} G=0
\end{aligned}
$$

\section{Characterization of an (interior) optimal investment $I_{A}$}

Here, we adopt a parametric configuration such that the constraint set is not empty. Under this circumstance, the constraint set is clearly bounded by 0 and $\mu t^{*}$ (i.e. the tax collection under full information). Moreover, this set is also closed because it is defined by weak inequalities and the functions $t(C)$ and $\pi(C)$ are continuos in $I$. Hence, the constraint set is compact. In addition, the maximand in $\mathcal{P}_{2}$ is also continuos in $I$. So, by the Weierstrass theorem (see Takayama 1985), the problem $\mathcal{P}_{2}$ has a maximum.

\section{$\underline{\text { First-order condition }}$}

To find the (interior) optimal investment $I_{A}$, the government solves the following problem

$$
\mathcal{P}_{2}\left\{\begin{array}{l}
\underset{I}{\operatorname{sax}_{\text {subject }} \quad \alpha \mu u(y-t)+\frac{1}{p}[\mu t-(1-\mu) \pi C-I]} \\
t=t(C), \pi=\pi(C)=1-\frac{u(y-t(C))}{u(y)} \\
C=c(I, \delta)
\end{array}\right.
$$

The first-order condition for an interior solution of problem $\mathcal{P}_{2}$ is given by

$$
\begin{aligned}
\frac{\partial \mathbb{E} \mathcal{W}^{A}}{\partial I}= & \frac{\partial t}{\partial C} c_{I} \underbrace{\left(-\alpha \mu u_{q}(y-t)+\frac{1}{p}\left[\mu-(1-\mu) C\left(\frac{u_{q}(y-t)}{u(y)}\right)\right]\right)}_{A} \\
& -\frac{1}{p}\left[(1-\mu) \pi c_{I}+1\right]=0
\end{aligned}
$$

Using (6), the term in parenthesis $A$ vanishes, so we can rewrite (8) as

$$
\frac{\partial \mathbb{E} \mathcal{W}^{A}}{\partial I}=-\frac{1}{p}\left[(1-\mu) \pi c_{I}+1\right]=0
$$




\section{Comparative statics}

From (9) and assuming that $Z=-(1-\mu)\left(\frac{\partial \pi}{\partial t} \frac{\partial t}{\partial C}\left(c_{I}\right)^{2}+\pi c_{I I}\right)<0$ (i.e. that the solution verifies second-order condition), we can apply the Implicit Function theorem and compute

$$
\begin{array}{ccc}
\frac{\partial I}{\partial \delta}=\frac{(1-\mu)\left[\frac{\partial \pi}{\partial t} \frac{\partial t}{\partial C} c_{\delta} c_{I}+\pi c_{I \delta}\right]}{Z} \gtrless 0 & \frac{\partial I}{\partial C_{0}}=\frac{(1-\mu)\left[\frac{\partial \pi}{\partial t} \frac{\partial t}{\partial C} c_{C_{0}} c_{I}+\pi c_{I C_{0}}\right]}{Z} \gtrless 0 \\
\frac{\partial I}{\partial \mu}=\frac{(1-\mu) \frac{\partial \pi}{\partial t} \frac{\partial t}{\partial \mu} c_{I}-\pi c_{I}}{Z} \gtrless 0 & \frac{\partial I}{\partial y}=\frac{(1-\mu)\left(\frac{\partial \pi}{\partial y}+\frac{\partial \pi}{\partial t} \frac{\partial t}{\partial y}\right) c_{I}}{Z}>0 \\
\frac{\partial I}{\partial \alpha}=\frac{(1-\mu) \frac{\partial \pi}{\partial t} \frac{\partial t}{\partial \alpha} c_{I}}{Z}<0 & \frac{\partial I}{\partial p}=\frac{(1-\mu) \frac{\partial \pi}{\partial t} \frac{\partial t}{\partial p} c_{I}}{Z}<0
\end{array}
$$




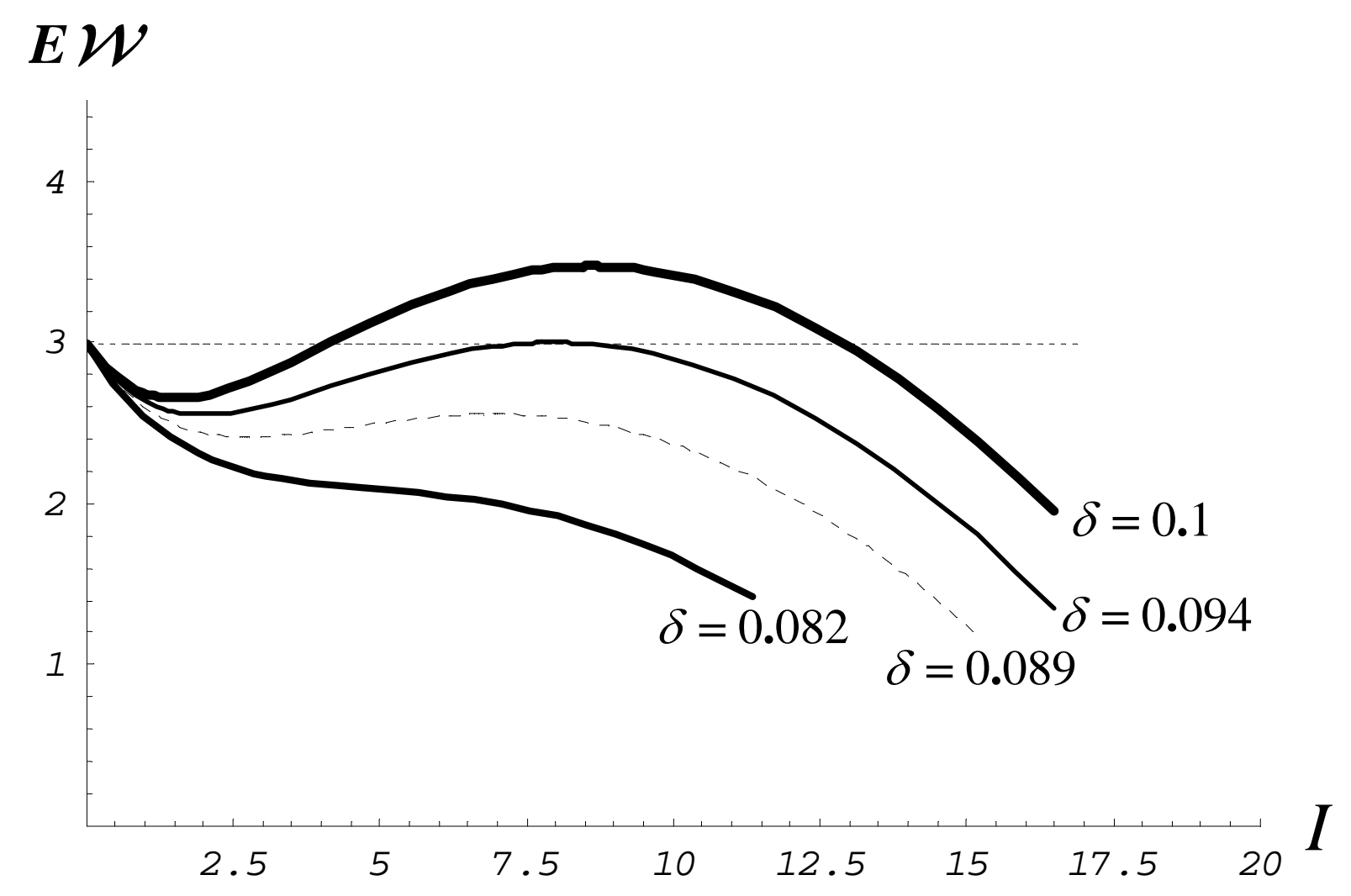

Figure 1: Jumps in the optimal investment 



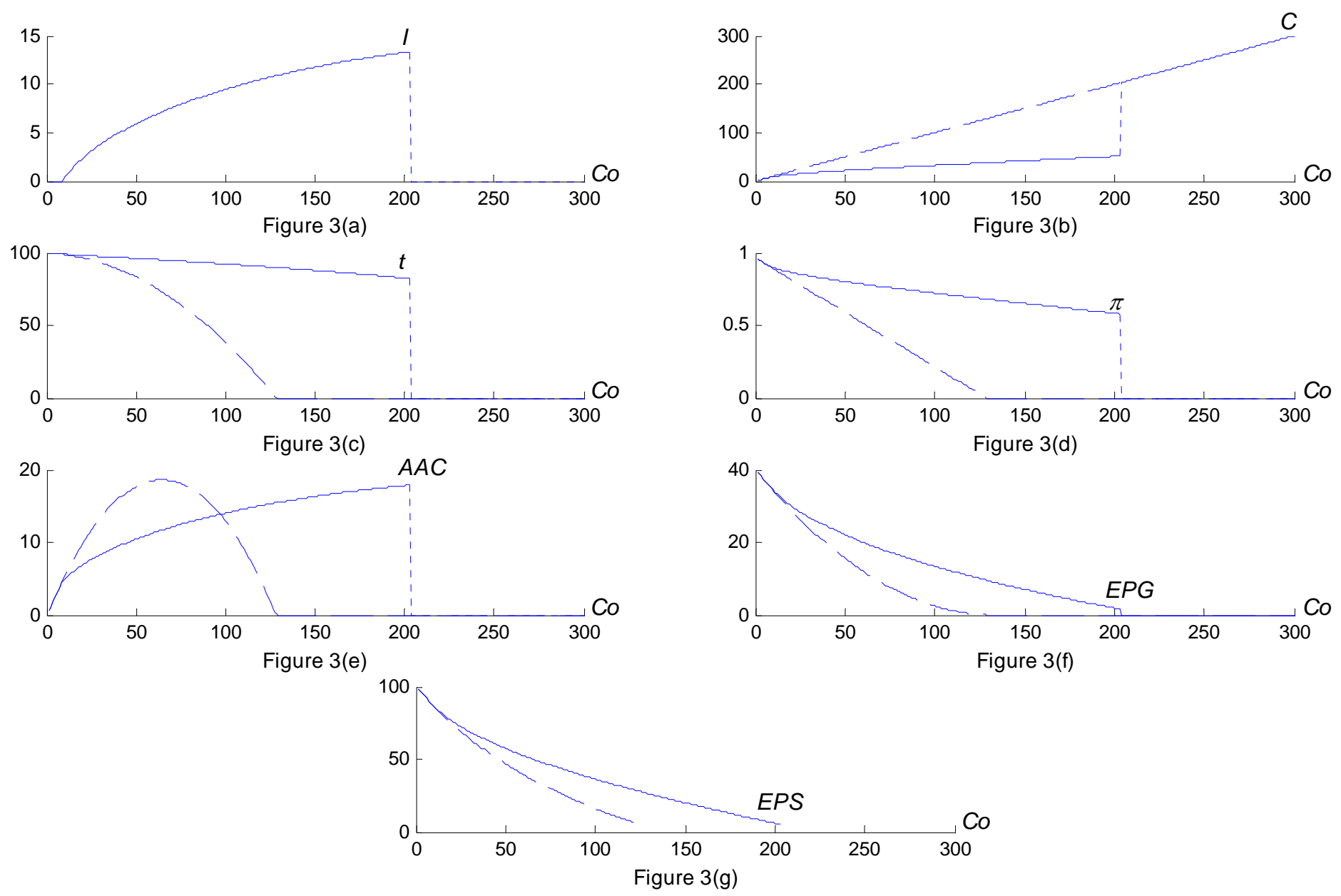

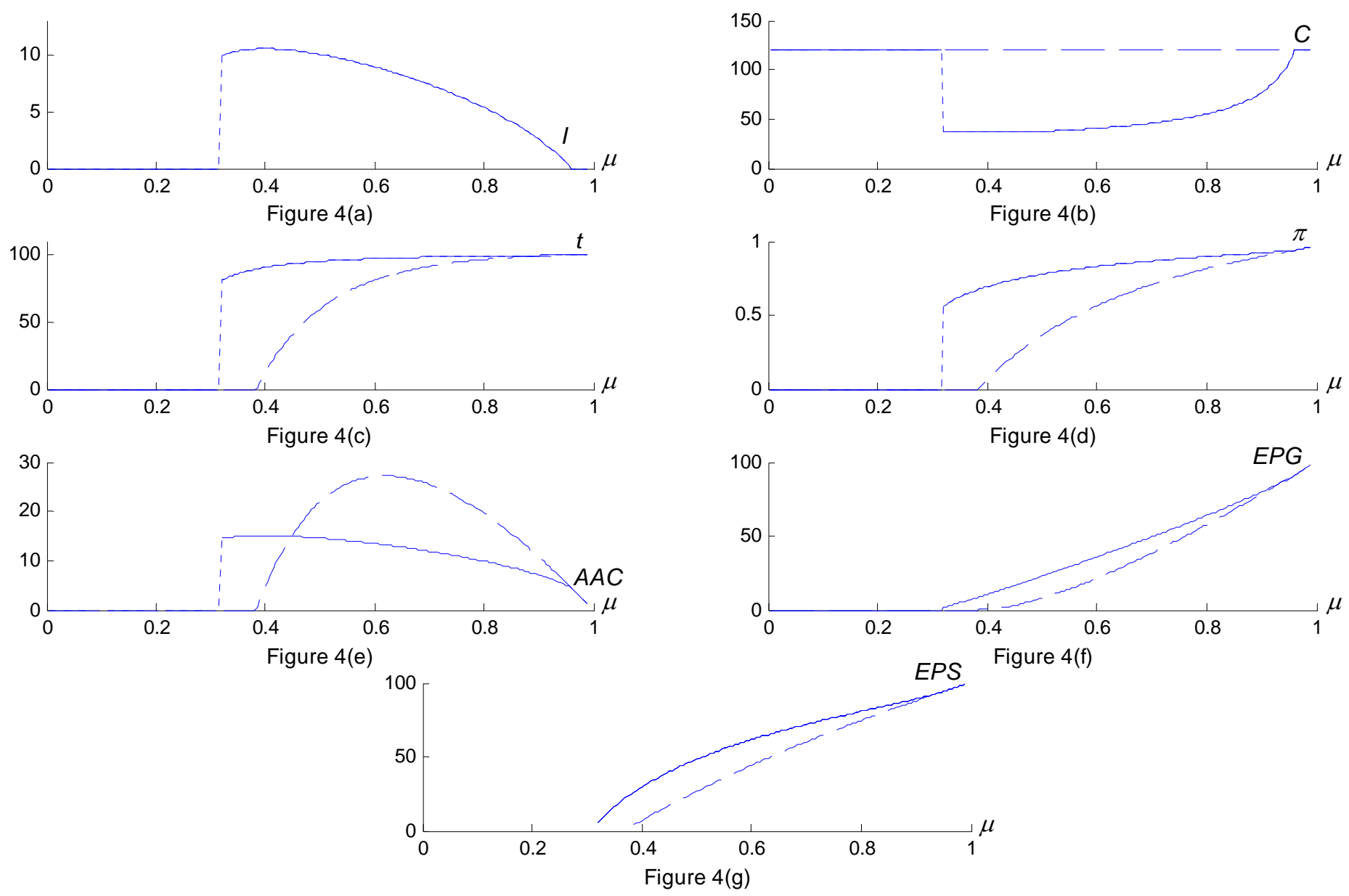

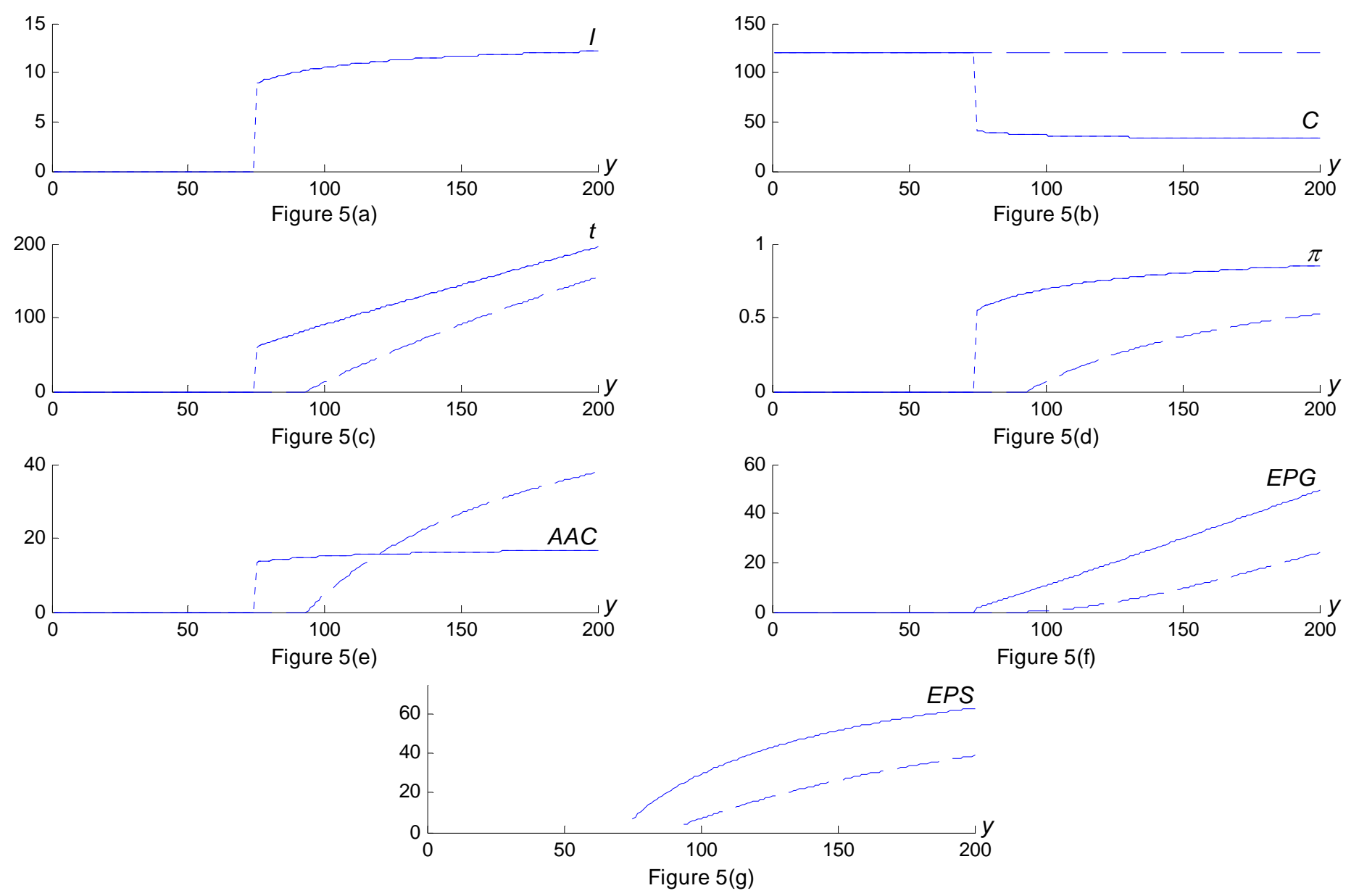